\title{
Efeito do fotoperíodo no crescimento e no padrão de acúmulo de frutanos em plantas aclimatizadas de Gomphrena macrocephala St.-Hil. (Amaranthaceae) ${ }^{1}$
}

\author{
MÍRIAM FERRAZ MOREIRA², CANDIDA C. J. VIEIRA ${ }^{3}$ e LILIAN B. P. ZAIDAN ${ }^{3,4}$
}

(recebido em 03/02/99; aceito em 19/08/99)

\begin{abstract}
Effect of photoperiod on growth and fructan accumulation pattern in acclimatized plants of Gomphrena macrocephala St.-Hil. (Amaranthaceae)). Gomphrena macrocephala is a perennial herb, native to the Brazilian cerrado, with medicinal properties and ornamental potential. As with other plants of the cerrado, it is characterized by well defined phenological phases. This species has been studied because of its particular fructan accumulation in the tuberous root, the variation of these carbohydrates being related with phenological phases. Micropropagated and acclimatized plants were used in the present study to investigate the presence of fructans in tuberous roots and to verify if the photoperiodic conditions interfere on growth, phenological behavior and on fructan accumulation. Short days $(8 \mathrm{~h})$ provided lower shoot growth, and induce the appearance of senescence characteristics and accumulation of polysaccharides, as already reported to plants in early dormancy. Long days (12 and $16 \mathrm{~h})$, however, increased shoot growth and resulted in lower fructan contents, similar to what is observed in the vegetative growth phase of this plant.
\end{abstract}

RESUMO - (Efeito do fotoperíodo no crescimento e no padrão de acúmulo de frutanos em plantas aclimatizadas de Gomphrena macrocephala St.-Hil. (Amaranthaceae)). Gomphrena macrocephala é uma espécie herbácea perene, nativa do cerrado brasileiro, que apresenta propriedades medicinais e potencial ornamental. Como outras espécies do cerrado, apresenta fases fenológicas bem definidas. A espécie tem sido estudada em função do acúmulo de carboidratos do tipo frutano em sua raiz tuberosa, cujo padrão de variação está relacionado com as fases fenológicas. O presente estudo utilizou plantas micropropagadas e aclimatizadas, com o objetivo de investigar a presença de frutanos em raízes tuberosas, além de verificar se as condições fotoperiódicas interferem no crescimento, no comportamento fenológico e no acúmulo de frutanos dessas plantas. Dias curtos (8 h) proporcionaram menor crescimento vegetativo, induziram o aparecimento de caracteres de senescência e acúmulo de polissacarídeos, como já descrito para plantas em início de dormência. Dias longos (12 e 16 h), no entanto, estimularam maior desenvolvimento da parte aérea e resultaram em menor conteúdo de frutanos, semelhante ao observado em plantas em fase de crescimento vegetativo.

Key words - Gomphrena, photoperiodism, fructan accumulation

\section{Introdução}

Gomphrena macrocephala (Amaranthaceae) é uma espécie herbácea perene que cresce espontaneamente no cerrado brasileiro (Vieira \& FigueiredoRibeiro 1993), apresentando ciclo de desenvolvimento anual, com fases fenológicas bem caracterizadas. No outono, a parte aérea da planta senesce e o órgão subterrâneo de reserva permanece dormente durante o inverno. Na primavera, ocorrem intensa brotação e crescimento vegetativo, vindo a planta a florescer e frutificar no verão. Esse padrão é comum a outras espécies herbáceas perenes do cerrado (Isejima \& Figueiredo-Ribeiro 1993, Carvalho \& Dietrich 1993). O comportamento fenológico desta vegetação reflete uma série de estratégias

1. Parte da dissertação de mestrado de M. F. Moreira (ESALQUSP).

2. Bolsista da CAPES

3. Seção de Fisiologia e Bioquímica, Instituto de Botânica, Caixa Postal 4005, 01061-970 São Paulo, SP, Brasil.

4. Autor para correspondência: lzaidan@smtp-gw.ibot.sp.gov.br adaptativas para superar estresses térmicos, hídricos e nutricionais (Mantovani \& Martins 1988). A redução na produção de matéria seca durante o outono e o inverno coincide com o período do ano em que ocorre menor disponibilidade de água, redução da temperatura e do comprimento do dia (Coutinho et al. 1982, Mantovani \& Martins 1988).

Pertencente à sub-classe Caryophyllidae, $G$. macrocephala é a única espécie deste grupo em que foi constatada a presença de frutanos, os quais representam cerca de $40 \%$ da matéria seca da raiz tuberosa (Vieira \& Figueiredo-Ribeiro 1993). Frutanos são carboidratos constituídos basicamente de séries homólogas de oligo e polissacarídeos não redutores contendo resíduos de frutose ligados a uma molécula de sacarose (Edelman \& Jefford 1968, Figueiredo-Ribeiro et al. 1991). São prontamente disponíveis e têm sido encontrados em órgãos de reserva de espécies herbáceas perenes do cerrado, principalmente nas asteráceas (Figueiredo-Ribeiro et al. 1991, Tertuliano \& Figueiredo-Ribeiro 1993). A presença de frutanos provavelmente confere às plantas maior capacidade de explorar ambientes em 
que a disponibilidade de água é limitada (Hendry 1993), como ocorre em regiões do cerrado. Nesse ambiente, os frutanos acumulados nos órgãos subterrâneos, além de atuar no armazenamento de energia, poderiam estar relacionados com processos de osmorregulação (Figueiredo-Ribeiro 1993).

Os frutanos acumulados nas raízes tuberosas de G. macrocephala estão distribuídos em série homóloga única e não correspondem à série da inulina (ligações ß-2,1) (Vieira \& Figueiredo-Ribeiro 1993), típica das dicotiledôneas (Pollock \& Chatterton 1988). A análise cromatográfica desses carboidratos e co-eluição com padrões conhecidos de frutanos sugeriram que os mesmos seriam do tipo B-2,6 (Vieira, 1996), predominante entre as gramíneas, porém não encontrado em dicotiledôneas. Utilizando métodos físico-químicos, Shiomi et al. (1996) confirmaram que os polissacarídeos de alto peso molecular de G. macrocephala são frutanos lineares do tipo fleano (levano) com ligações ß-2,6.

Vieira \& Figueiredo-Ribeiro (1993) observaram a ocorrência de variações sazonais na quantidade e na composição dos frutanos de G. macrocephala. No final da dormência, ocorre aumento no teor de polissacarídeos concomitante à redução na quantidade de oligossacarídeos. Nas fases de brotação e crescimento vegetativo, predominam frutanos de baixo peso molecular. Nos períodos de floração/ frutificação e início de dormência, há um aumento no peso molecular dos polissacarídeos e redução no teor de oligossacarídeos.

Além dos frutanos, G. macrocephala acumula saponinas esteroidais (Young et al. 1992). A presença de grandes inflorescências purpúreas, do tipo capítulo, amplia a potencialidade de uso dessa espécie, tanto para fins econômicos como ornamentais (Vieira et al. 1994).

G. macrocephala é uma espécie de difícil propagação. A reprodução vegetativa pode ocorrer através de brotações de gemas localizadas na raiz tuberosa, porém esse processo é limitado, tendo em vista o lento crescimento das raízes. A reprodução sexuada é também restrita, em função do reduzido número de sementes viáveis produzidas (Vieira et al. 1994).

A micropropagação foi, então, sugerida como uma alternativa viável para a multiplicação dessa espécie (Mercier et al. 1992). Estudos prévios (Vieira 1996) mostraram que tecidos cultivados in vitro, incluindo raízes adventícias de plantas micropropagadas, acumulam frutanos. No entanto, esses frutanos são exclusivamente do tipo inulina, ao contrário das raízes de plantas propagadas em condições naturais, que acumulam fleanos.

O objetivo deste trabalho foi investigar a presença de frutanos em raízes tuberosas de plantas aclimatizadas de Gomphreana macrocephala e verificar se as condições fotoperiódicas são capazes de influenciar o desenvolvimento das plantas, interferindo no comportamento fenológico e no acúmulo de carboidratos nas raízes tuberosas.

\section{Material e métodos}

As sementes de Gomphreana macrocephala St.-Hil. foram coletadas em região de cerrado no município de Itirapina, SP $\left(22^{\circ} 18^{\prime} \mathrm{S}\right.$ e $\left.47^{\circ} 11^{\prime} \mathrm{W}\right)$. Um exemplar dessa população foi depositado no Herbário do Estado "Maria Eneyda P. Kauffmann Fidalgo" (SP167648), do Instituto de Botânica. As plantas matrizes foram obtidas a partir de germinação de sementes in vitro. Microestacas desenvolvidas a partir de gemas axilares dos explantes nodais retirados das plântulas in vitro (Mercier et al. 1992) foram enraizadas em meio MS (Murashige \& Skoog 1962) desprovido de fitorreguladores. Após 30 dias em meio de enraizamento, as plantas foram transferidas, individualmente, para bandejas de plástico contendo terra de cerrado.

A aclimatização foi feita em casa de vegetação, com luz natural, temperatura de $28^{\circ} \mathrm{C} \pm 3^{\circ} \mathrm{C}$, umidade relativa de $95 \%$ e irrigação por nebulização cerca de oito vezes ao dia, durante 50 dias.

Os tratamentos fotoperiódicos foram iniciados após esse período (março de 1998). Para cada tratamento fotoperiódico ( $8 \mathrm{~h}$, $12 \mathrm{~h} \mathrm{e} 16 \mathrm{~h}$ ) foram utilizadas 12 plantas, em vasos individuais. Todas as plantas receberam $8 \mathrm{~h}$ de luz natural em casa de vegetação com irradiância média correspondente a $80 \%$ da irradiância natural. A fim de complementar o fotoperíodo necessário, o tempo de exposição à luz foi suplementado em câmaras com controle automático de iluminação, conforme descrito em Ruggiero \& Zaidan (1997). A irrigação foi feita diariamente ou quando se fez necessário.

A cada 20 dias foram observados o número de pares de folhas, o comprimento da haste e o número de novas brotações.

Para as análises de frutanos, amostras de raízes tuberosas de duas plantas de cada tratamento foram retiradas 140 dias após o início do tratamento fotoperiódico. As amostras foram separadas em três partes, cada uma constituindo uma repetição. Foram então pesadas, congeladas $\left(-80^{\circ} \mathrm{C}\right)$ e liofilizadas, até atingirem peso constante, para determinação da massa seca.

A extração de frutanos a partir das amostras liofilizadas das raízes tuberosas foi feita de acordo com o método estabelecido por Pollock \& Jones (1979), adaptado para G. macrocephala, conforme descrito em Vieira \& Figueiredo-Ribeiro (1993). Os extratos foram cromatografados no sistema "Dionex", que consiste na cromatografia de troca aniônica de alto desempenho (HPAEC), usando-se colunas CarboPac' PA1 (4 x $250 \mathrm{~mm}$ ) e CarboPac' PA100 (4 x $250 \mathrm{~mm}$ ), com detecção de pulso amperométrico (PAD). A eluição dos carboidratos foi realizada conforme método utilizado por Shiomi et al. $(1991,1996)$. Os resultados foram registrados através de um integrador Hewlett- 
Packard, sendo comparados com extratos de raízes tuberosas de G. macrocephala coletadas no cerrado e de tubérculos de Helianthus tuberosus, preparados conforme método descrito por Pollock \& Jones (1979), utilizados como padrão

A quantificação de frutose total, livre e combinada, foi feita segundo Jermyn (1956), utilizando D-frutose como padrão e expressa como média dos valores obtidos.

Com o intuito de verificar o tipo de frutano presente em plantas aclimatizadas após um longo período, foi também avaliado o carboidrato acumulado em plantas aclimatizadas após dois anos, utilizando-se a mesma metodologia descrita acima.

\section{Resultados e Discussão}

Os valores médios de crescimento da parte aérea (comprimento de haste e número de pares de folhas) foram maiores quando as plantas foram submetidas aos fotoperíodos mais longos (12 h e $16 \mathrm{~h}$ ), conforme é mostrado na tabela 1 e na figura 1. Dias mais longos aparentemente favoreceram o aparecimento de maior número de brotações, a partir de gemas localizadas na porção basal da raiz tuberosa (tabela 1). Esses resultados sugerem que os parâmetros de crescimento analisados são influenciados pelo fotoperíodo. Thomas \& Vince-Prue (1997) afirmam ser possível generalizar que plantas submetidas a dias longos apresentam maior crescimento vegetativo, algumas vezes diretamente em função do fotoperíodo, outras como resultado da atividade fotossintética.

Tabela 1. Dados de crescimento (média \pm desvio padrão) em altura, número de pares de folhas e número de brotações em plantas micropropagadas e aclimatizadas de Gomphrena macrocephala mantidas em fotoperíodos de 8,12 e 16 h por 140 dias.

\begin{tabular}{cccc}
\hline Fotoperíodo & $8 \mathrm{~h}$ & $12 \mathrm{~h}$ & $16 \mathrm{~h}$ \\
\hline $\begin{array}{c}\text { Comprimento } \\
\text { da haste }(\mathrm{cm})\end{array}$ & $4,17 \pm 0,16$ & $10,73 \pm 0,99$ & $12,25 \pm 2,20$ \\
$\mathrm{~N}^{\mathrm{o}}$ de pares & & & \\
de folhas & $2,79 \pm 0,13$ & $3,66 \pm 0,17$ & $3,06 \pm 0,24$ \\
$\mathrm{~N}^{\mathrm{o}}$ de brotações & $1,00 \pm 0,08$ & $1,15 \pm 0,07$ & $1,26 \pm 0,07$ \\
\hline
\end{tabular}

No estado de São Paulo, a variação do fotoperíodo é de 10,5 a 13,5 horas (Vianello \& Alves 1991). Tendo em vista que em $G$. macrocephala houve menor produção de folhas nos fotoperíodos de $8 \mathrm{~h}$ e 16 h, é possível que fotoperíodos aquém ou além da faixa natural de variação possam constituir uma condição desfavorável para o crescimento de

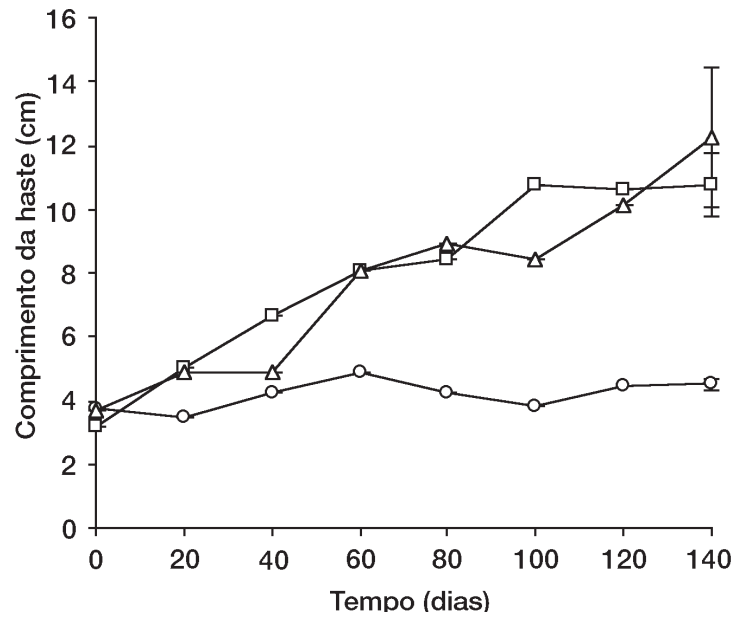

Figura 1. Curva de crescimento de plantas micropropagadas e aclimatizadas de Gomphrena macrocephala durante 140 dias de tratamento fotoperiódico $(8(-\infty-), 12(-\square-)$ e $16(\neg-)$ horas). As barras representam o desvio padrão da média.

algumas espécies que ocorrem nesta região, conforme já descrito em outras espécies (Ruggiero \& Zaidan 1997). Klein et al. (1996) observaram que plantas de Bidens gardneri Baker, uma espécie herbácea perene, também do cerrado, apresentaram maior desenvolvimento da parte aérea em fotoperíodos intermediários $(12 \mathrm{~h}, 14 \mathrm{~h}, 16 \mathrm{~h})$, tendo registrado valores menores de crescimento nas plantas mantidas em fotoperíodos mais curtos $(8 \mathrm{~h})$ ou mais longos $(20 \mathrm{~h})$ do que os mencionados.

Menor crescimento vegetativo foi observado quando as plantas foram submetidas a fotoperíodo de $8 \mathrm{~h}$ (tabela 1, figura 1). Este resultado coincide com os dados observados para outras espécies perenes do cerrado, como Viguiera discolor (Isejima et al. 1991), Vernonia cognata (Cesarino 1996), Viguiera robusta (Ruggiero \& Zaidan 1997) e Diplusodon virgatus (Cesarino et al. 1998). Algumas plantas de $G$. macrocephala em fotoperíodo de $8 \mathrm{~h}$ apresentaram características de senescência e perderam a parte aérea durante o período de estudo. No entanto, não foi possível afirmar que essas plantas poderiam estar em dormência, ou que foram induzidas à dormência por dias curtos. G. macrocephala, quando em condições naturais, apresenta menor crescimento e perde a parte aérea, entrando em dormência no final do outono, quando o fotoperíodo está gradativamente diminuindo (Vieira \& FigueiredoRibeiro 1993). 
A tabela 2 mostra os valores de massa fresca e seca e os teores de frutose total das raízes tuberosas de G. macrocephala nos diferentes tratamentos fotoperiódicos após 140 dias. A massa fresca total foi maior nas plantas em fotoperíodo de $16 \mathrm{~h}$. No entanto, os dados de massa seca foram muito semelhantes nos três fotoperíodos. Com relação à frutose total, só é possível afirmar que os menores valores foram encontrados no fotoperíodo de $8 \mathrm{~h}$. Os altos valores do desvio padrão da média em $16 \mathrm{~h}$ impedem outras conclusões.

Tabela 2. Valores de massa fresca total $(\mathrm{g})$, valores médios de massa seca/massa fresca $(\mathrm{g})$ e de frutose total (mg. $\mathrm{g}^{-1}$ massa seca) encontrados na raiz tuberosa de plantas de Gomphrena macrocephala, após 140 dias de tratamento fotoperiódico.

\begin{tabular}{cccc}
\hline Fotoperíodo & $\begin{array}{c}\text { Massa } \\
\text { fresca }\end{array}$ & $\begin{array}{c}\text { Massa seca/ } \\
\text { massa fresca }\end{array}$ & $\begin{array}{c}\text { Frutose } \\
\text { total }\end{array}$ \\
\hline $8 \mathrm{~h}$ & 1,24 & $0,26 \pm 0,056$ & $14,20 \pm 3,22$ \\
$12 \mathrm{~h}$ & 2,67 & $0,23 \pm 0,072$ & $26,20 \pm 4,69$ \\
$16 \mathrm{~h}$ & 4,89 & $0,30 \pm 0,059$ & $51,30 \pm 22,91$ \\
\hline
\end{tabular}

Análise dos carboidratos por HPAEC mostraram a presença de uma série homóloga de frutanos (figura 2) que co-eluíram com os fleanos extraídos de raízes tuberosas de plantas de $G$. macrocephala coletadas no cerrado. No presente estudo, fleanos de baixo peso molecular estão presentes nas raízes tuberosas das plantas de todos os tratamentos fotoperiódicos, porém em proporções inferiores às encontradas para glicose, frutose e sacarose (figura 2). Em nenhum tratamento fotoperiódico foi detectado frutano do tipo inulina, como encontrado em calos oriundos da parte aérea de G. macrocephala, cultivados in vitro (Vieira et al. 1995). Esse resultado mostra que as plantas micropropagadas, depois de um período de aclimatização, passaram a apresentar acúmulo do mesmo tipo de frutano que plantas propagadas por sementes. Isto foi particularmente evidente nas plantas micropropagadas e aclimatizadas, cultivadas por dois anos em casa de vegetação (figura 2), em cujas raízes tuberosas foram detectados os membros de baixo peso molecular da série homóloga de fleanos.

$\mathrm{O}$ acúmulo de frutanos em órgãos perenes, tais como tubérculos e raízes tuberosas, pode ser afetado por fatores externos e por processos de desen- volvimento que alteram a partição de compostos de reserva (Pollock \& Chatterton 1988, FigueiredoRibeiro 1993). Carvalho et al. (1997), trabalhando com Vernonia herbacea, uma espécie de Asteraceae nativa do cerrado, observaram que o teor de oligossacarídeos foi maior durante o período de rápido crescimento vegetativo, concomitante à redução no teor de polissacarídeos. A variação nos teores de frutano indicou que este carboidrato é metabolizado durante o desenvolvimento da planta. O mesmo foi observado em plantas de G. macrocephala submetidas aos fotoperíodos mais longos (12 e 16 h), onde a proporção de oligossacarídeos da série de frutanos foi superior àquela de polissacarídeos (figura 3). Raízes tuberosas de plantas submetidas a fotoperíodo de $8 \mathrm{~h}$ apresentaram uma proporção elevada de polissacarídeos em relação aos oligossacarídeos quando comparada aos demais tratamentos. Isejima et al. (1991), estudando a influência do fotoperíodo em Viguiera discolor, observaram que, embora a quantidade total de frutanos das raízes tuberosas tenha sido similar nos tratamentos de dias curtos e longos, a relação polissacarídeos: oligossacarídeos foi de 10:1 em dias curtos e 6:1 em dias longos. Esses autores mostraram ainda que os polissacarídeos de inulina predominaram nas raízes tuberosas em todos os tratamentos, ocorrendo em maior quantidade nas plantas induzidas para floração.

A floração em plantas de G. macrocephala não foi observada em nenhum dos tratamentos fotoperiódicos, mesmo depois de nove meses de cultivo. Existem poucos dados disponíveis sobre a floração de espécies do cerrado, conforme mencionado na revisão feita por Zaidan \& Felippe (1994). Além do fotoperíodo, outros fatores ambientais, como temperatura e umidade, exercem efeito importante na indução da floração (Thomas \& VincePrue 1997).

Estudos feitos em condições de casa de vegetação, utilizando plantas do cerrado portadoras de órgão subterrâneo de reserva e que foram irrigadas periodicamente, mostraram que essas plantas apresentam fases fenológicas coincidentes com as observadas em plantas crescendo naturalmente no cerrado (Figueiredo-Ribeiro \& Dietrich 1981, Isejima \& Figueiredo-Ribeiro 1993, Carvalho \& Dietrich 1993, Sá e Carvalho \& Dietrich 1996, Carvalho et al. 1997). O presente estudo limitou-se a 

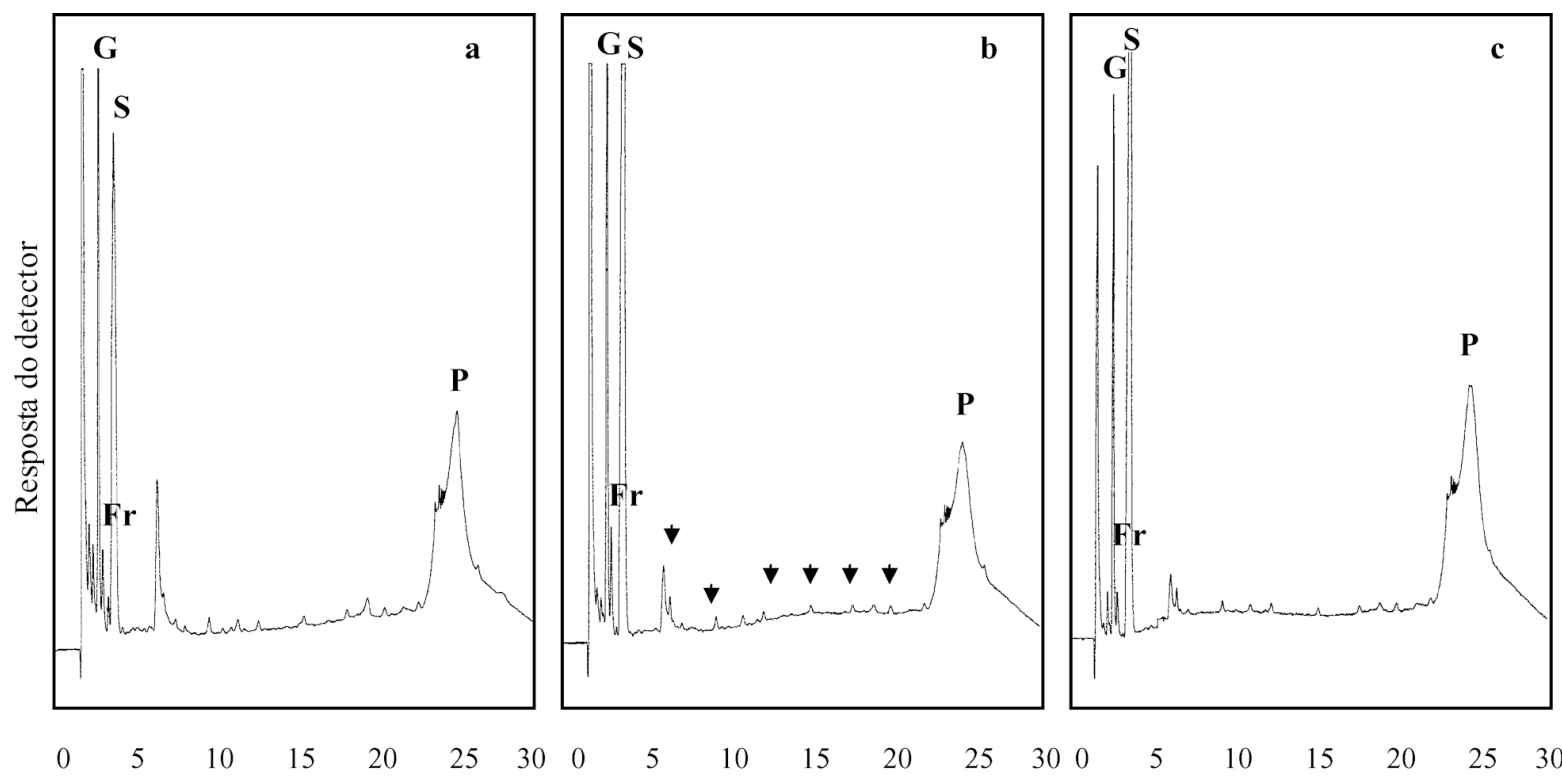

$10 \quad 15 \quad 20$

25300

$\begin{array}{llll}5 & 10 & 15 & 20\end{array}$
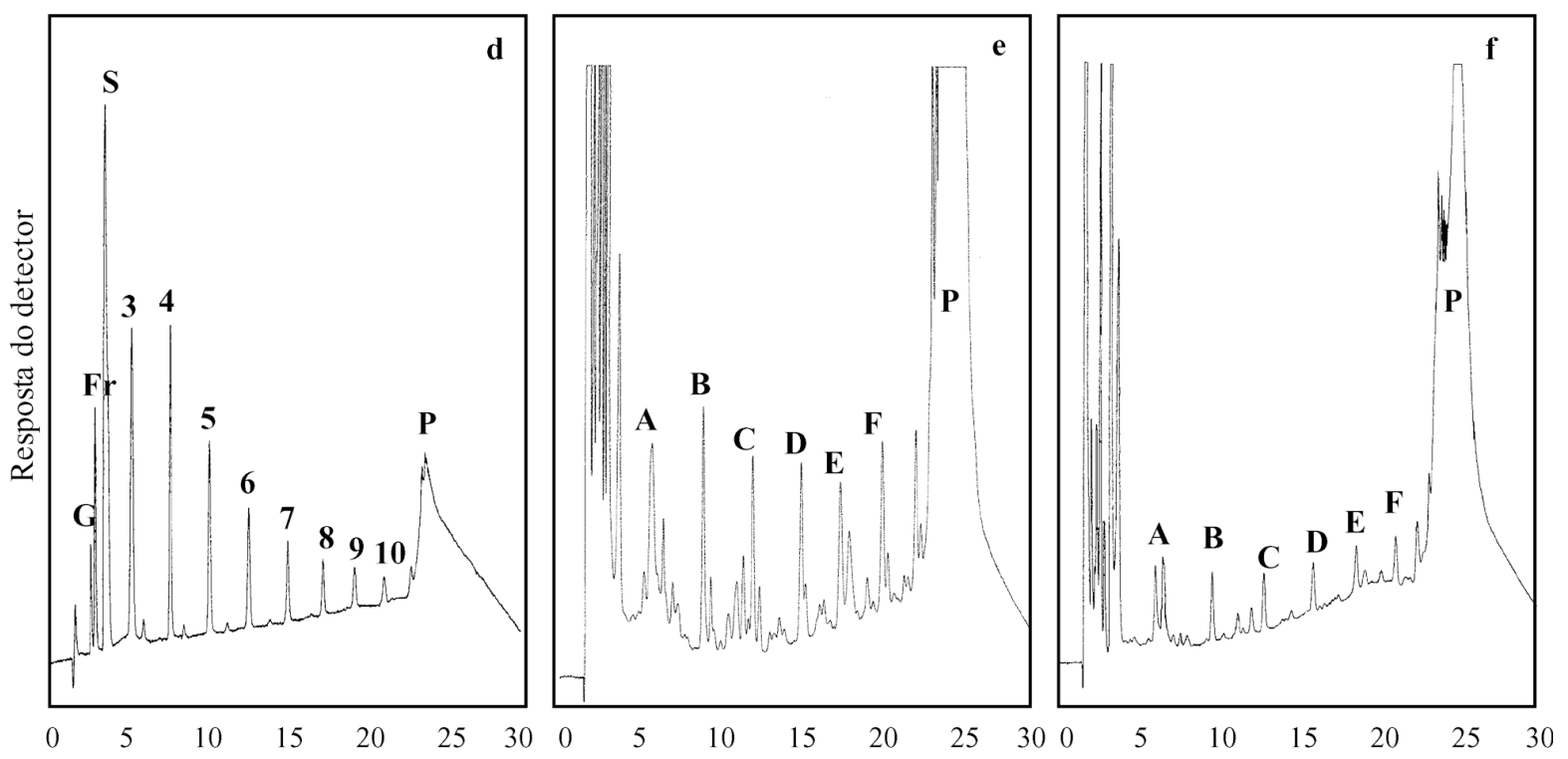

Tempo de eluição (min)

Figura 2. Análise por HPAEC, em coluna CarboPac PA1, dos oligossacarídeos presentes em raízes tuberosas de plantas micropropagadas e aclimatizadas de Gomphrena macrocephala, submetidas a fotoperíodos de 8(a), 12(b) e 16(c) horas por 140 dias. Os perfis cromatográficos foram comparados com padrões conhecidos de oligossacarídeos de inulina, obtidos de tubérculos de Helianthus tuberosus(d) e de fleanos, extraídos de raízes tuberosas de plantas de G. macrocephala, coletadas no campo(e), e de plantas micropropagadas e aclimatizadas com dois anos de idade(f). G, glucose; Fr, frutose; S, sacarose; P, polissacarídeos; 3-10, oligossacarídeos de inulina com grau de polimerização 3 a 10; A-F e setas, oligossacarídeos da série homóloga de fleanos de $G$. macrocephala. 

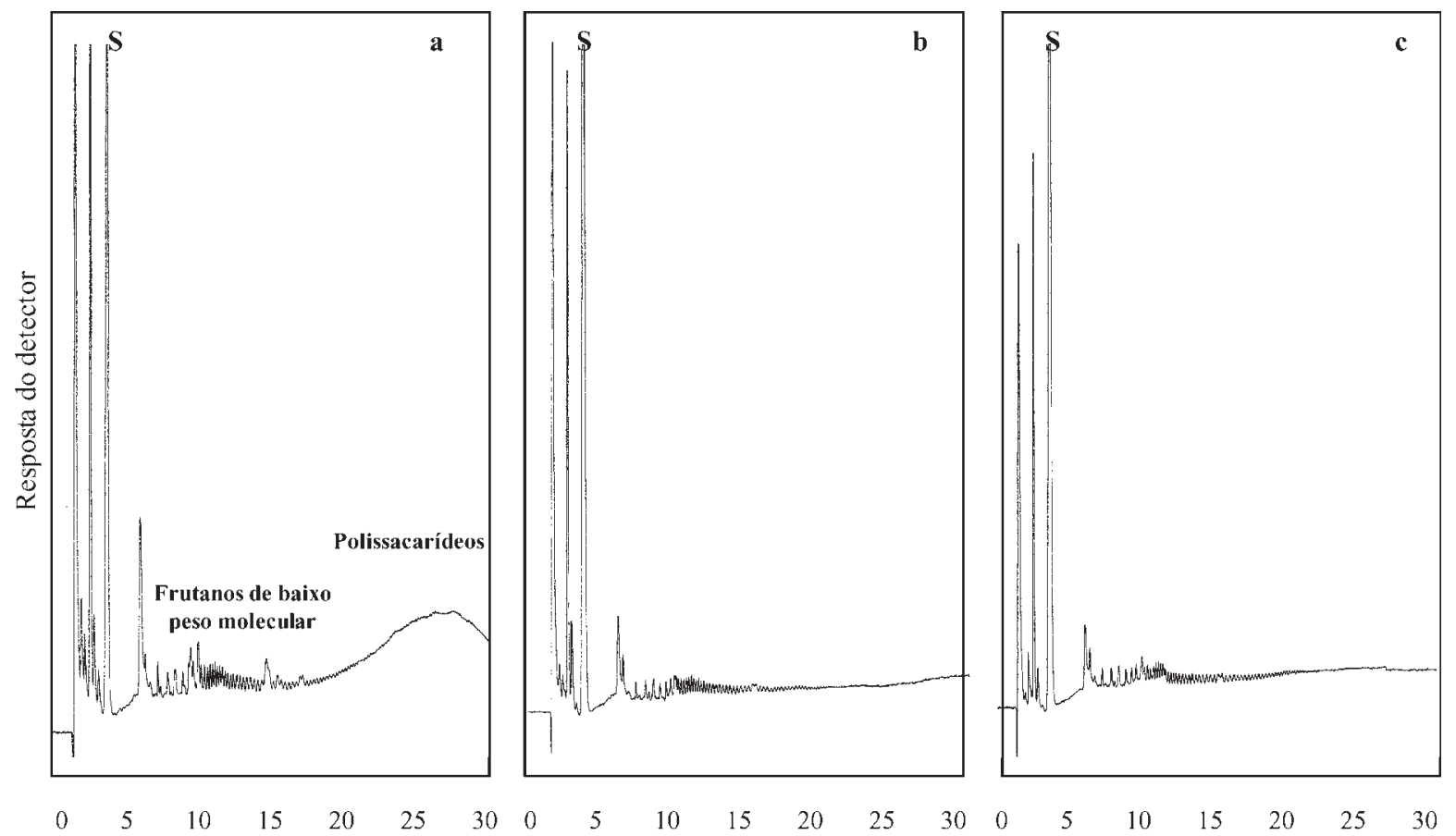

Tempo de eluição (min)

Figura 3. Análise por HPAEC, em coluna CarboPac PA100, dos polissacarídeos de raízes tuberosas de plantas micropropagadas e aclimatizadas de Gomphrena macrocephala, submetidas a fotoperíodos de 8(a), 12(b) e 16(c) horas por 140 dias. S, sacarose.

um período de nove meses que procedeu a etapa de aclimatização. Embora não tenham sido observadas as fases fenológicas já descritas para $G$. macrocephala (Vieira \& Figueiredo-Ribeiro 1993), especialmente floração e dormência, não se pode deixar de considerar que as plantas aqui estudadas originaram-se de segmentos caulinares de plântulas. Sendo assim, é provável que necessitem de um período de dormência antes de iniciar um ciclo de desenvolvimento, como já foi descrito para $V$. herbacea (Carvalho et al. 1997). Plantas de G. macrocephala crescendo em canteiros próximos à casa de vegetação apresentaram floração coincidindo com o período em que florescem no cerrado (verão). Estas plantas, propagadas vegetativamente a partir de estacas radiculares de plantas trazidas do cerrado, têm, portanto, um comportamento diferente do das microestacas formadas a partir de plântulas cultivadas in vitro.

Variações no teor de frutanos podem ocorrer ao longo do ciclo de vida das plantas acumuladoras, tanto em monocotiledôneas como em dicotiledôneas (Pontis 1989). Vieira \& Figueiredo-Ribeiro (1993) relacionaram as variações na composição, no conteúdo e no peso molecular dos frutanos de $G$. macrocephala com os estados fenológicos da planta. Apesar das diferenças observadas nos tratamentos fotoperiódicos em relação ao crescimento da parte aérea das plantas de G. macrocephala (tabela 1) e ao conteúdo de frutose total das raízes tuberosas (tabela 2), não foram constatadas alterações significativas na proporção de oligo e polissacarídeos (figura 3), com exceção do tratamento fotoperiódico de $8 \mathrm{~h}$. Vieira \& Figueiredo-Ribeiro (1993) observaram um padrão característico para os carboidratos de G. macrocephala em cada fase fenológica. De fato, plantas que cresceram em fotoperíodo de $8 \mathrm{~h}$ apresentaram características morfológicas (ramos secos, folhas com manchas purpúreas, ausência de gemas em brotação) e bioquímicas (acúmulo de polissacarídeos) de plantas em estado de dormência.

Agradecimentos - Ao CEBTEC, especialmente ao Dr. Otto J. Crocomo, pelo uso dos laboratórios e da casa de vegetação, possibilitando a multiplicação in vitro e a aclimatização das plantas estudadas. 


\section{Referências bibliográficas}

CARVALHO, M.A.M. \& DIETRICH, S.M.C. 1993. Variation in fructan content in the underground organs of Vernonia herbacea (Vell.) Rusby at different phenological phases. New Phytologist 123:735-740.

CARVALHO, M.A.M., ZAIDAN, L.B.P. \& DIETRICH, S.M.C. 1997. Growth and fructan content of plants of Vernonia herbacea (Asteraceae) regenerated from rhizophores. New Phytologist 136:153-161.

CESARINO, F. 1996. Crescimento de Vernonia cognata Less., uma espécie herbácea de cerrado. Tese de mestrado, Universidade Estadual de Campinas, Campinas.

CESARINO, F., ARAUJO, J.E. \& ZAIDAN, L.B.P. 1998. Germinação de sementes e crescimento de plantas de Diplusodon virgatus Pohl, Lythraceae. Acta Botanica Brasilica 12(supl.): 349-356.

COUTINHO, L.M., VUONO, Y.S. \& LOUSA, J.S. 1982. Aspectos ecológicos do fogo no cerrado. IV. A época da queimada e a produtividade primária líquida epigéia do estrato herbáceo subarbustivo. Revista Brasileira de Botânica 5:37-41.

EDELMAN, J. \& JEFFORD, T.G. 1968. The mechanism of fructosan metabolism in higher plants as exemplified in Helianthus tuberosus. New Phytologist 67:517-531.

FIGUEIREDO-RIBEIRO, R.C.L. 1993. Distribuição, aspectos estruturais e funcionais dos frutanos, com ênfase em plantas herbáceas do cerrado. Revista Brasileira de Fisiologia Vegetal 5:203-208.

FIGUEIREDO-RIBEIRO, R.C.L. \& DIETRICH, S.M.C. 1981 Variações estacionais nos compostos de reserva e no metabolismo do xilopódio de Ocimum nudicaule Benth. var. anisifolia Giul. (Labiatae). Revista Brasileira de Botânica 4:73-82.

FIGUEIREDO-RIBEIRO, R.C.L., ISEJIMA, E.M., DIASTAGLIACOZZO, G.M., CARVALHO, M.A.M. \& DIETRICH, S.M.C. 1991. The physiological significance of fructan accumulation in Asteraceae from the Cerrado. Ciência e Cultura 43:443-446.

HENDRY, G.A.F. 1993. Evolutionary origins and natural functions of fructans - a climatological, biogeographic and mechanistic appraisal. New Phytologist 123:3-14.

ISEJIMA, E.M. \& FIGUEIREDO-RIBEIRO, R.C.L. 1993. Fructan variations in tuberous roots of Viguiera discolor Baker (Asteraceae): the influence of phenology. Plant and Cell Physiology 34:723-727.

ISEJIMA, E.M., FIGUEIREDO-RIBEIRO, R.C.L. \& ZAIDAN, L.B.P. 1991. Fructan composition in adventitious tuberous roots of Viguiera discolor Baker (Asteraceae) as influenced by daylength. New Phytologist 119:149-154.

JERMYN, M.A. 1956. A new method for the determination of ketohexoses in presence of aldohexoses. Nature 177:38-39.

KLEIN, A.L., ZAIDAN, B.P. \& FELIPPE, G.M. 1996. Interaction between soil and photoperiod on development of Bidens gardneri Baker (Asteraceae), a herbaceous species from the Brazilian cerrado. Revista Brasileira de Botânica 19:1-15.

MANTOVANI, W. \& MARTINS, F.R. 1988. Variações fenológicas das espécies de cerrado da Reserva Biológica de Mogi-Guaçu, São Paulo. Revista Brasileira de Botânica 11:101-112.

MERCIER, H., VIEIRA, C.C.J. \& FIGUEIREDO-RIBEIRO, R.C.L. 1992. Tissue culture and plant propagation of Gomphrena officinalis - a Brazilian medicinal plant. Plant Cell, Tissue and Organ Culture 28:249-254.
MURASHIGE, T. \& SKOOG, F. 1962. A revised medium for rapid growth and bioassays with tabacco tissue culture. Physiologia Plantarum 15:473-497.

POLLOCK, C.J. \& CHATTERTON, N.J. 1988. Fructan. In Biochemistry of plants (J. Preiss, ed.). Academic Press, London, p.109-140.

POLLOCK, C.J. \& JONES, T. 1979. Seasonal patterns of fructan metabolism in forage grasses. New Phytologist 83:8-15.

PONTIS, H.G. 1989. Fructans and cold stress. Journal of Plant Physiology 134:148-150.

RUGGIERO, P.G.C. \& ZAIDAN, L.B.P. 1997. Estudos de desenvolvimento de Viguiera robusta Gardn., uma Asteraceae do Cerrado. Revista Brasileira de Botânica 20:1-9.

SÁ e CARVALHO, C.G. \& DIETRICH, S.M.C. 1996. Carbohydrates in tuberous roots of Cochlospermum regium in different stages of development. Revista Brasileira de Botânica 19:127-131.

SHIOMI, N., ONODERA, S., CHATTERTON, J. \& HARRISON, P.A. 1991. Separation of fructooligosaccharide isomers by anion-exchange chromatography. Agricultural and Biological Chemistry 55:1427-1428.

SHIOMI, N., ONODERA, S., VIEIRA, C.C.J. \& FIGUEIREDORIBEIRO, R.C.L. 1996. Structure of fructan polymers from tuberous roots of Gomphrena macrocephala St.-Hil., a herbaceous Amaranthaceae from the cerrado. New Phytologist 133:643-650

TERTULIANO, M.F. \& FIGUEIREDO-RIBEIRO, R.C.L. 1993. Distribution of fructose polymers in herbaceous species of Asteraceae from the cerrado. New Phytologist 123:741-749.

THOMAS, B. \& VINCE-PRUE, D. 1997. Photoperiodism in plants. Academic Press, San Diego.

VIANELLO, R.L. \& ALVES, A.R. 1991. Meteorologia básica e aplicações. Imprensa Universitária, Viçosa.

VIEIRA, C.C.J. 1996. Caracterização e produção de frutanos por tecidos e órgãos isolados de Gomphrena macrocephala St.-Hil. (Amaranthaceae). Tese de doutorado, Universidade de São Paulo, São Paulo.

VIEIRA, C.C.J. \& FIGUEIREDO-RIBEIRO, R.C.L. 1993. Fructose - containing carbohydrates in the tuberous root of Gomphrena macrocephala St. Hil. (Amaranthaceae) at different phenological phases. Plant, Cell and Environment 16:919-928.

VIEIRA, C.C.J., MERCIER, H., CHU, E.P. \& FIGUEIREDORIBEIRO, R.C.L. 1994. Gomphrena species (globe amaranth): In vitro culture and production of secondary metabolites. In Biotecnology in Agriculture and Forestry (Y.P.S. Bajaj, ed.). Springer-Verlag, Berlin \& Heidelberg, v.28, p.257-270.

VIEIRA, C.C.J., BRAGA, M.R. \& FIGUEIREDO-RIBEIRO, R.C.L. 1995. Fructans in callus of Gomphrena macrocephala St.-Hil. Plant Cell, Tissue and Organ Culture 42:233-238.

YOUNG, M.C.M, VIEIRA, C.C.J., CHU, E.P., HARAGUCHI, M. \& FIGUEIREDO-RIBEIRO, R.C.L. 1992. Ecdysterone and saponins from tuberous roots of Gomphrena officinalis Mart. (Amaranthaceae). Revista Latinoamericana de Química $22 \&$ 23: 41-44.

ZAIDAN, L.B.P. \& FELIPPE, G.M. 1994. Flowering of cerrado plants: experiments in semi-controlled environmental conditions. Flowering Newsletter 18:4-11. 